\title{
Empirical Macromodels Under Test \\ A Comparative Simulation Study of the Employment Effects \\ of a Revenue Neutral Cut in Social Security Contributions
}

Herbert S. Buscher, Hermann Buslei, Klaus Göggelmann, Henrike Koschel,

Fred Ramb, Tobias F. N. Schmidt, Viktor Steiner and Peter Winker ${ }^{1}$

JEL classification: C50, C53, E17, H55

Mannheim, November 1998

This is a preliminary version; please do not quote without the permission of the authors.

${ }^{1}$ ZEW, Mannheim, except Peter Winker, University of Mannheim. 


\begin{abstract}
In the paper we simulate a revenue-neutral cut in the social security contribution rate using five different types of macro- / microeconomic models, namely two models based on time-series data where the labour market is modelled basically demand oriented, two models of the class of computable equilibrium models which are supply oriented and finally a firm specific model for international tax burden comparisons. Our primary interest is in the employment effects the models predict due to the cut in the contribution rate. It turns out that qualitatively all models considered predict an increase in employment three years after the cut. But the employment effects differ considerably in magnitude, which follows immediately from the different behavioral assumptions underlying the different models.
\end{abstract}

\title{
Zusammenfassung
}

In dem Beitrag wird der Beschäftigungseffekt infolge einer aufkommensneutralen Senkung der Sozialversicherungsbeiträge simuliert. Zu diesem Zweck werden fünf unterschiedliche ökonomische Modelle verwendet, namentlich zwei Modelle, die auf Zeitreihendaten aufbauen und in denen der Arbeitsmarkt überwiegend von der Nachfrageseite dominiert wird, zwei Modelle aus der Klasse der computable equilibrium models, die typischerweise angebotsorientiert sind, und ein mikroökonomisches, firmenspezifisches Steuerbelastungsvergleichsmodell. Alle Simulationsergebnisse der Modelle weisen auf einen, wenngleich teilweise kleinen, positiven Beschäftigungseffekt hin, der sich allerdings beträchtlich in seiner Größenordnung unterscheidet. Dies ist eine unmittelbare Folge aus den unterschiedlichen Verhaltensannahmen, die den einzelnen Modellen unterliegen. 


\section{Introduction and overview ${ }^{2}$}

High and persistent unemployment in many European countries is one of the major, if not the major concern of current economic policy analysis. The different developments in several European countries that led to the current unemployment issue do not allow for a monocausal interpretation, but it seems that the wedge between producer and consumer wages by a growing share of contributions to the social security systems is one potential factor. The increase in contributions is partly endogeneous to the labor market, since it is caused by the increasing transfers to the growing number of unemployed. On the other hand, nearly all western European countries are characterized by a rapidly aging society resulting in larger contributions to the pension insurances under a pay as you go system.

It seems obvious that a reduction in social security contributions through a reduction of unit labor costs is one among several options to improve the international competitiveness of enterprises, which further on will lead to an improved employment situation in the future. The effects of a reduced contribution rate on employment has been analyzed for a number of countries in different settings and using alternative modelling approaches. ${ }^{3}$ Entorf, König and Pohlmeier [1992] evaluate the employment effects by keeping nonwage labor costs fixed from a certain year (1981) on. They use a macroeconometric disequilibrium model for the West German labor market of the Sneessens-Drèze-type and conclude that four years later employment would have risen by about 1.1 million employees and the unemployment rate would be 2.4 percentage points lower compared with the base year. But it should be noted that no financing aspects are considered. Conrad and Schmidt [1997] analyze the effects of the introduction of a $\mathrm{CO}_{2}$ emission tax on employment when the additional tax receipts are used to reduce the contribution rate to the social security system. Within the framework of a computable general equilibrium model they report on a possible double dividend effect (reduction of $\mathrm{CO}_{2}$ emission and employment growth), depending on the labor market specification (neoclassical or more Keynesian-like) as well as on a unilateral or multinational introduction of the new tax. The OECD [1994] job study summarizes the results for Germany that increases in both employers' and employees' social security contributions, the income tax as well as indirect taxes lead to proportionate increases in real labor costs in the long run, although there are some important differences in the short-run. Due to the chosen model structure, at least in the long-run the employment effects of shifting the burden of financing the social security system from contribution rates to direct or indirect taxation may be rather modest. Franz, Göggelmann and Winker [1997] use a macroeconometric disequilibrium model for West Germany to simulate the employment effects of a revenue neutral cut in the contribution rate of the social security system. Employment effects are most likely to occur when the labor unions behave co-operative in wage negotiations. Furthermore, employment effects of the cut are higher when the economy is in a capacity regime and significantly lower when in the demand regime.

The objective of this paper does not consist in contributing another result for a different setting or using a different modelling approach. Instead, a comparative simulation study is used to assess the impact of the modelling approach. The reference scenario chosen for this comparison is a reduction of the payments to the social security system which is financed by an increase in indirect tax rates, implying that in the first year after the change the reduced receipts to the social security system are fully compensated by a corresponding increase in the receipts of

\footnotetext{
${ }^{2}$ We thank the seminar participants in Konstanz for their valuable comments. Nevertheless, all errors remain in the responsibility of the authors.

3 See e.g. Entorf, König, Pohlmeier [1992], Franz, Göggelmann, Winker [1997], OECD Jobs Study [1994], Pissarides [1998] and Conrad and Schmidt [1997].
} 
indirect taxes. Our interest concentrates on the employment effects simulated by different modelling approaches and on the economic mechanisms driving these results.

In the study we simulate the employment effects of a revenue neutral cut in social security contributions using five differently structured models, namely

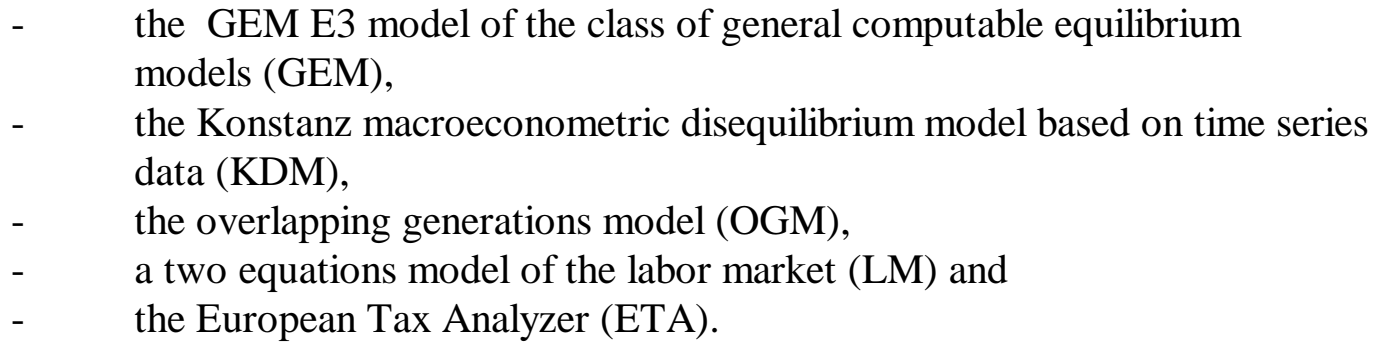

These five models selected for the simulation study cover in a broad sense a large part of modelling approaches used for the purpose at hand. ${ }^{4}$ They cover partial and total analyses, equilibrium and disequilibrium models, econometrically estimated, calibrated and ad hoc quantified models.

To start with the most general one ${ }^{5}$, the GEM E3 model is a long-term computable general equilibrium model designed for the analysis of environmental problems. ${ }^{6}$ The second model is a macroeconometric disequilibrium model of the West German economy developed to explain fluctuations in the goods and the labor marktes. Both macro models fully account for feedback effects from other markets as well as of the rest of the world and thus allow the analysis of the total impact on the system due to changes in certain variables. The third model, an overlapping generations model, was built to mainly analyze the long-term development of the German pension system under alternative reform options. Although the model is still under construction, preliminary results are already available.

The fourth model is an aggregated two equations model of the West German labor market with a demand for labor equation as well as an equation that explains the wage behavior in the West German economy. In its present structure feedbacks from other markets, national or international, are not allowed for. The final model - the European Tax Analyzer (ETA) - is micro in its structure, since only the partial effect on producer wages is mirrored. It is developed to analyze the change in the tax burden of a typical industrial enterprise due to changes in the tax system or in different taxes across countries.

The paper is organized as follows: In the next section a short description of the different models used in the simulation study is given. In the third and the fourth section we describe the simulation experiment, present and discuss the results. In the final section we summarize the main outcomes and conclusions and offer some suggestions for further research.

\section{A Brief Description of the Models Used in the Simulation Study}

\footnotetext{
${ }^{4}$ For a more detailed description of the destinction between macroeconometric and CGE approaches in policy modelling see e.g. Capros, Karadeloglou, Mentzas [1990] and Fehr and Wiegard [1996].

5 The ordering of the models was from general to specific. The most general one relates to the openness of an economy as well as the number of domestic markets considered.

${ }^{6}$ CGE-models are also used in the analysis of optimal taxation, labor market developments and foreign trade; see e.g. Bovenberg and Goulder [1996], Bovenberg and de Mooij [1994 a,b], Hansen and Heckman [1996] and Shoven and Whalley [1984, 1992].
} 
Macroeconomic models are used to analyze, to forecast and to simulate various economic situations. They provide quantitative information on certain economic policies, and are applied to test the validity of theoretical statements as well as to develop and analyze alternative economic scenarios. However, macroeconomic models which are able to provide adequate answers to all economical questions do not yet exist. Depending on the specific problem different models have to be used.

Models differ in their time horizon. Problems related to business cycle fluctuations, for instance, can be solved by using short- or medium-term models, ignoring long-term implications or developments such as changes in the population. On the other hand long-term models explicitly deal with changes in population, in natural resources, environmental conditions and the like, ignoring short-term fluctuations in the economy. Depending on the time horizon of the models their results may differ or may even be contradictory. Obviously, there is no guarantee a priori that models with different time horizons as well as different objectives will produce similar results.

Another criterion to classify macroeconomic models relates to the level of aggregation. The more disaggregated a model is, the more important the correct modelling of the transmission mechanism becomes. An imprecise or wrong modelling of the transmission mechanism may lead to biased estimates and to wrong policy conclusions. On the other side, highly disaggregated or large-scale models have the advantage of delivering detailed information about the impact of shocks on different markets and are thus improving our understanding of the interdependencies between markets and sectors. Highly aggregated models avoid the need to model the different transmission mechanisms and concentrate on a few behavioral equations that explain the most important macroeconomic variables. Highly aggregated models are usually very flexible and require much less effort for their construction and updates. But this flexibility is linked with a loss in information and the risk of not covering the main mechanisms and behavioral patterns that drive the system as well as the outcome.

The traditional economic model building approach is based on the assumption that all markets are in equilibrium. A shock disturbs this initial equilibrium temporarily, works itself throught the model structure and ends up with a new equilibrium. A different approach consists in an explicit modelling of disequilibrium situations. However, this strategy depends on observable and reliable data on disequilibrium situations. Attempts to model disequilibrium on some markets explicitly, among others, have been developed by Fair and Jaffé [1972] by introducing econometric disequilibrium models. The first generation of disequilibrium models is characterized by an exogeneous determination of the regime switching points to determine the kind of disequilibrium in a special market. This artificial assumption and the lack of data made this type of model rather short-lived. Nevertheless, recent developments in disequilibrium econometrics led to a solution of the above mentioned problems. Based on microeconomic principles the former approach applies to a micro market, but at the aggregate level it is possible to determine the regime shifts endogenously by use of observable data. One of these new disequilibrium models is the so-called Konstanz Disequilibrium Model which we describe below.

Both types of models - equilibrium as well as disequilibrium models - use time-series data at the macro level and estimate the unknown coefficients of the behavioral equations by appropiately chosen estimation techniques. Model updates will then usually lead to slightly different coefficient estimates, given a fairly stable structure of the model. 
An alternative class of models which has been applied widely in the last twenty years, mainly in the area of taxation, international trade and energy policies, are computable general equilibrium models (CGE). These models convert the Walrasian general equilibrium structure, formalized by Arrow and Debreu in the 1950s, from an abstract into a realistic representation of an actual economy (see Shoven and Whalley [1992]). These models are used to analyze the impacts of different policies on the resource allocation and on the distribution of benefits and costs across sectors, social groups or countries. Particularly, the evaluation of distributive effects represents a main advantage of CGE models over other more aggregated macroeconomic models. A common feature of CGE models is that they make use of the calibration technique. Production and demand parameters are calculated in such a way that the inital (base-year) equilibrium observation is exactly replicated by the model. The so-called benchmark equilibrium data set that represents the equilibrium of an economy is often based on Input-Output-tables and national accounting statistics as well. Nevertheless, due to an under-identification problem, some parameters such as elasticity values entering CES or LES functions, have to be specified exogenously. Usually, the required values are taken from the literature and represent econometric estimates from time-series studies or economically plausible values. Although the deterministic calibration procedureis often critizised, it shows some advantages over stochastic time-series estimation (see Shoven and Whalley [1992], p. 106). Firstly, calibrated CGE models that incorporate many thousands of parameters do not rely (primarily) on time-series data but only on a single observation. This means the researchers are not ,plagued“ by finding appropriate data as well as a sufficient number of observations. Therefore, calibration models can operate at a higher disaggregation level. Besides, they can be used for countries where data availability is rather poor. Secondly, benchmark data sets that are given in value terms have to be decomposed into separate price and quantity observations. Thus, using the time-series estimation procedure would be difficult since a sequence of equilibrium observations with consistent units through time is required.

Within the class of computable equilibrium models Fehr and Wiegard [1996] distinguish between static, sequentially dynamic as well as completely dynamic models. The latter subgroup can be further divided into the Ramsey-type class of models and into overlapping generations models. Out of the class of CGE-models we consider a variant of a sequentially dynamic model, the so-called GEM-E3-model. As a second member of the class of CGE-models we use an overlapping generations model (with an uncertain point of death for its members) was developed primarily to analyze the consequences of alternative financing strategies on the pension insurance fund.

The last model considered is the so-called European Tax Analyzer. The Tax Analyzer considers a typical enterprise in the industrial sector and calculates the effective tax burden the firm is confronted with in different countries or regions for comparison purposes.

For all the reasons mentioned above and for many more, different models - designed for different economic policy problems - will not generally produce identical results, even if the same economic policy action is simulated. Therefore, it is necesaary to compare the basic features to understand the driving forces of the different models. The next subsections give a brief overview of the models used in this simulation study. In order to facilitate comparison across models we use a taxonomy which is given in the following Table 1.

Table 1: Taxonomy Used for Model Comparison

\section{a) General characteristics}

type of model (equilibrium model, disequilibrium model, etc.) 
primarily objective of the model

main emphasis of research

dynamics and time horizon

open vs. closed economy

inputs of the models

model closure

\section{b) Special characteristics}

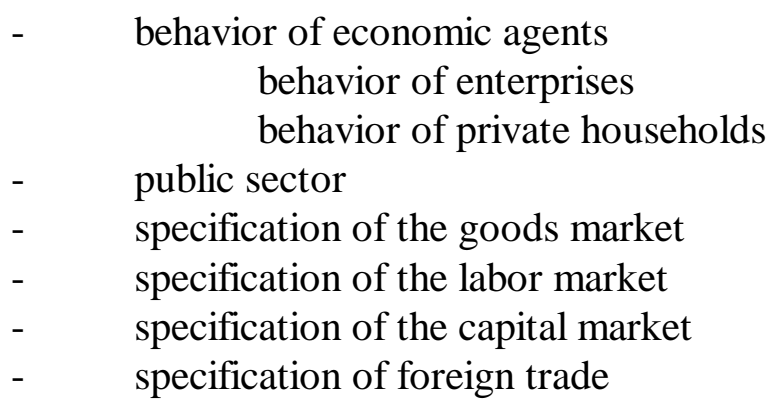

c) Model output

d) Model specific strengths and weaknesses, possible extensions

\section{The General Equilibrium Model: GEM-E3 Model (GEM)}

\section{General characteristics}

The GEM-E3 General Equilibrium Model for Energy-Economy-Environment interactions, partly financed by the European Commission ${ }^{7}$, has been developed in cooperation with various European research institutes for the European Union member states. GEM-E3 can be classified as a multi-period, multi-country, multi-sectoral computable general equilibrium model that provides details on the macro-economy and its interactions with the environment and the energy system. The model computes the equilibrium prices of goods, labor and capital that simultaneously clear all markets under the Walras law. The model's main objective is to serve as a quantitative tool for analyzing structural change and distributional effects across countries as well as across economic and social groups within each country. The policy activities being analyzed cover general economic policies like public finance, taxation and social policy as well as environmental policy issues in particular the analysis of environmental policy instruments. GEM-E3 is an open economy model that represents all EU member states, either non-linked or linked through endogenous bilateral trade flows. thus, it can be used to compare co-ordinated versus non co-ordinated policies in the European Union.

The GEM-E3-model obeys a recursive static structure which generates sequential equilibria consecutively for each period. These sequential period equilibria are functionally related to a combined stock-flow accumulation of physical capital and environmental pollution. Additional driving forces of the system dynamics result from the myopic expectations of the agents and from autonomous technical progress.

\footnotetext{
${ }^{7}$ JOULE program, co-ordinator P. Valette (DG-XI//F1)
} 
Although the model has no specific time horizon, it is basically a long-term model designed for analyzing the effects of policies over a period of ten to twenty years. In the present version, the model contains fourteen European Union countries. The definition of economic agents and their transactions follows the framework of a Social Accounting Matrix (SAM). A SAM is an extended Input-Output-table which is complemented by a table of income flows and transfers between agents. the entire database of the model consists of a SAM per country (i.e. fourteen), bilateral trade matrices (country by country and per product), an environmental database and a set of parameter values which is obtained by calibration or by relying on literature-based parameter estimates (e.g. elasticities of substiution in standard CES production functions).

As equilibrium in standard (real) CGE models depends on relative prices only, there is one degree of freedom left. To obtain an overall equilibrium a so called macro-closure of the model has to be chosen. Like most other comparable model specifications GEM-E3 uses the neoclassical closure, that is it equals investment and savings by adapting the corresponding global shadow price of capital. The model is constructed in such a way that the equilibrium of this market is satisfied automatically by Walras' Law.

\section{Special characteristics of the model}

GEM-E3 is a general purpose model that aims to cope with the specific orientation of the policy issues that are actually considered at the level of the European Commission. Therefore, it is modularly built by allowing the user to select among several alternative behavioral / closure options depending on the particular issue of interest. For instance, some important options refer to

- $\quad$ capital mobility across sectors and / or countries

- $\quad$ flexible or fixed current account (with respect to the foreign sector)

- $\quad$ flexible and fixed public deficit

- $\quad$ flexible or fixed labor supply

- $\quad$ different market competition regimes

- $\quad$ IS-LM closure.

The central CGE core of GEM-E3 is a macro-economic model which is based on microeconomic behavioral principles of economic agents and on several institutional features. The economic agents are producers, households, government and foreign sector.

In GEM-E3, the producers are represented by 18 sectors of the Input-Output framework. Each sector (one representative firm per sector) is assumed to produce a single product with constant returns to scale. Following a nested CES functional form, production is modelled through KLEM - (capital, labor, energy and materials) production functions, involving two primary factors - capital and labor - and 18 intermediate goods.

Energy inputs are further disaggregated into electricity, coal, oil and gas to account for the primary use of the model for environmental policy analyses. The firms aim at maximizing their profits in the short run, restricted by a fixed physical capital stock and available technology. Changes of a firm's capital stock over time are realized by investment. Sectoral investment matrices translate sectoral investment demand into demand for intermediate products.

Consumer demand and labor supply are used to model the behavior of a representative private household, who aims at maximizing his intertemporal utility (modelled by a Stone-Geary-utility function) under an intertemporal budget constraint, assuming myopic expectations. For the 
household sector as an aggregate, a nested intertemporal linear expenditure system is derived. Firstly, the household determines an allocation of his resources between present and future consumption. Then, for an expected income in period $t$ the household determines his period level of consumption and the amount of leisure he prefers. With leisure determined, the labor supply follows as the difference between total time resources and desired level of leisure. On two further stages, expenditure is allocated on thirteen consumption categories, including durable and non-durable goods. Again a bridge matrix is used to translate demand by consumption categories into final demand of products of the Input-Output framework.

In the standard version of GEM-E3 the market clearing proceeds under perfect competition assumptions, in particular, it is assumed that wages are flexible. But the model also allows for wage rigidities. Contrary to labor, the model assumes that capital is flexible on an international scale. But in line with the labor market assumptions capital is treated as a homogeneous good which is traded in completely competitive markets.

The public sector is to a large extent exogenously given. The model distinguishes nine different revenue categories with exogenously given rates on alternative tax bases. Among these categories are indirect and direct taxes, VAT, social security contributions, import duties as well as energy and environmental taxes. Total government consumption consists of public consumption as well as public investment, both are assumed to be exogenous to the model.

In GEM-E3, the EU-country models are linked by bilateral trade flows. Within the EUcountries it is assumed that imports and domestic production of tradable and competitive goods are not perfect substitutes (Armington assumption), i.e. the import demand function partly depends on price relations. World production and export prices are given exogenously, i.e. export supply is perfectly price elastic. To ensure a zero trade deficit (in value) at the global level, imports by one country are set equal to the corresponding exports of another country (in volume and value).

The economic CGE core of the GEM-E3 model is completed by the environmental module which allows for analysis of policy induced changes of the state of the environment. this icludes the emission computation for primary pollutants like $\mathrm{CO}_{2}, \mathrm{SO}_{2}$ and $\mathrm{NO}_{\mathrm{x}}$, $\mathrm{VOC}$ or particulates and secondary pollutants like ozone as well as the consideration of transboundary air pollution and the evaluation of environmental damages.

\section{Model Results}

From an economic point of view the solution of the model delivers equilibrium values for the main basic macroeconomic variables such as GDP, employment, trade flows, investment or consumption. These values are reported for each country as well as for each sector within an economy. From a policy point of view the model finishes with a welfare measure based on an equivalent variation (EV) of alternative policy activities. The improvement or deterioration of environment elicited from a particular policy is reflected by the change in emissions and damages. The damages are part of the welfare measure applied.

\section{Strengths and weaknesses of the model, possible extensions}

A general advantage of the GEM-E3 model is the micro-economic foundation of the behavioral equations which allows a consistent modelling of observable interdependency in the real world as well as the simultaneity of economic decisions. In particular, technical (=IO-) coeffi- 
cients in production and demand are flexible and price-dependent. Main advantages of this type of model also can be seen in the explicit treatment of environmental problems as well as in its European dimension.

Under the standard working conditions the model assumes perfect competition, but this assumption may be relaxed when it seems appropriate. For instance, the basically neoclassically structured labor market can be modified to account for the problem of involuntary unemployment by relaxing the assumption of a market-clearing wage rate.

Current short-comings and possible extensions and objectives of the on-going development of the GEM-E3 model relate to alternative market clearing mechanisms, disaggregated specification of the labor market in labor skills, the endogenous representation of technology evolution and the engineering representation of the energy system, to mention the most important issues (see Capros et al. [1997], p. 67).

\section{The Konstanz Macroeconomic Disequilibrium Model (KMD-Model)}

\section{General characteristics of the model}

The Konstanz Disequilibrium $\mathrm{Model}^{8}$ is a medium-sized quarterly macroeconometric model for the West German economy including, among others, the goods and labor markets as the main building blocks. In this sense it is primarily developed to analyze the real activities of a small open economy. The philosophy behind the model building strategy is Neo-Keynesian macroeconomics, i.e. one of the basic assumptions relates to the idea of not permanently cleared markets. This temporary disequilibrium induces adjustment processes in the quantities traded in each market due to the corresponding excess supply or demand situation. Prices are assumed to adjust only slugglishly in the short run. A cornerstone in the model building process is the conception of the economy as being composed of many micro markets, where each single micro market refers to a homogenous product or a firm which produces a homogenous good and can be characterized by excess demand or by excess supply. Explicit aggregation over these micro markets determines the share of markets being in a specific regime. Therefore, at the aggregate level different regimes can be observed at the same time and changes of regimes take place continuously.

The Konstanz disequilibrium model was constructed to analyze different causes of unemployment on an empirical basis. ${ }^{9}$ Recent research focusses mainly on the factors driving the demand for labor as well as on the investment behavior.

The model uses quarterly data for West Germany, starting in 1960 up to 1994. Almost all equations are estimated in an error-correction specification, which mirror short-term deviations from some long-term relationship, which, however, is not necessarily an equilibrium in the neoclassical interpretation. The time horizon of simulations with this model ranges between three to ten years to cover both short-run dynamics and the tendency towards the long-run solution.

The disequilibrium model accounts for the openness of the West German economy by specifying the international trade via export and import equations. Especially imports play a prominent

\footnotetext{
${ }^{8}$ For a detailed description of the model see Franz, Göggelmann and Winker [1997, 1998], Franz and König [1990], Franz and Smolny [1992] and Franz, Göggelmann, Schellhorn and Winker [1998].

9 A comprehensive study on the causes of the European unemployment is provided by Drèze and Bean [1990].
} 
role in the determination of the disequilibrium situation in the economy. Based on time series data all behavioral equations are estimated by least squares or simultaneous equation approaches to obtain estimates of the unknown coefficients. The model is closed by introducing explicitly some definitorial identities of national accounting.

\section{Special features of the model}

Disequilibrium models of the first generation ${ }^{10}$ are based on the strong „minimum condition“ which, in the present case, says that observed employment is determined by the smaller quantity of the demand for and the supply of labor. With respect to observed labor market behavior this minimum condition is unable to explain the contemporaneous existence of unemployment and vacancies, the so called mismatch. In addition, the strong minimum condition implies immediate discontinuous jumps between different regimes when applied at a macro level. The Konstanz Disequilibrium Model instead applies the strong minimum condition on micro markets and avoids the above mentioned critism $^{11}$ by appropriately aggregation over the micro markets. The basic advantage of this view is that although regime changes may occur in a rather abrupt way on micro markets, the regime shift will appear much smoother and more gradually at a macro level. One reason for this different macro results stems from the fact that the model implicitly considers a large number of micro markets which are, at a given point in time, in different disequilibrium situations.

Actual employment is determined through a CES-function, using labor demand and labor supply as arguments. The central parameter of the CES-function relates to the variance of the disturbances in theses markets. The larger the variance of disturbances, the smaller the value of the parameter. At the macro level, if this parameter tends to infinity the strong minimum condition will apply. For labor and capacities it is assumed that adjustment is possible only in the medium or in the long term, respectively. Therefore, labor demand on the micro markets is determined by the minimum of labor input necessary to satisfy the demand for goods and the number of employees which can be employed profitably for a given capacity level.

A similar approach is adopted to the goods market. Again, the model starts at the micro level by determining the production, employment and investment decisions of the representative firm.

Two important features of the model serve to be mentioned here. The first feature refers to the aggregate demand for goods which consists of public and private consumption, public and private investment, exports and imports. For the first four components it is assumed that no rationing of the demand will occur. Therefore, an existing disequilibrium in the good markets manifests itself in a gap between effective imports and effective exports. A key element of this assumption consists in dividing the imports into two parts: the first part corresponds to the effective demand for foreign goods and the second part reflects the amount of excess demand in the domestic good market. To distinguish between these two components empirically it is assumed that observed and effective imports are identical when the domestic rate of capacity utilization has reached a historical minimum.

\footnotetext{
10 As an example consider the disequilibrium model developed by Fair and Jaffé [1972]. Although the model was developed to analyze the U.S.-housing market, the basic principles of first stage disequilibrium models can be found there. See also Bowden [1978] for further developments in the econometrics of disequilibrium.

11 See e.g. Lambert [1988].
} 
The second main feature relates to the productivity equations. These equations model the substitution between labor and capital due to changes in the relative factor prices. These equations can be used to test the assumption of a slow adjustment of the input factors to the optimal levels as well as the assumption of a short-term limitational production technology. The optimal factor inputs are determined under the assumption of profit maximization for a given linear homogeneous CES-production technology.

In a second step the estimated productivities are used to determine the maximum quantity of goods supplied for a given level of employment on one hand; on the other hand the productivities can be used to determine the quantity of labor necessary to produce the aggregate demand of goods. Given this framework, the model determines for each point in time the regime shares and the corresponding levels of employment. The regime shares are defined as the share of enterprises belonging to one regime relative to the total number of enterprises.

\section{Model result}

As one important output the model presents information about the regime shares over time and, therefore, identifies different sources of unemployment.

\section{Model strengths and weaknesses, possible extensions}

One of the most notable features of the Konstanz Disequilibrium Model is the capability to allow for different states of rationing at the same time on the aggregate level. Given the high level of aggregation structural analyses are somewhat cumbersome to conduct. Still an unsolved problem relates to the mismatch in the labor market. Up to now it was impossible to endogenize this mismatch completely. Model extensions relate to the inclusion of the public sector with special emphasis on the investment behavior of the government. Currently, the model is updated to cover the time period up to 1997 including East Germany. Moreover, the modelling of the supply side of the economy deserves greater attention.

\section{An Overlapping Generations Model (OLG)}

\section{General characteristics ${ }^{12}$}

This model is a computable general equilibrium model with overlapping generations in the tradition of the OLG model invented by Auerbach and Kotlikoff [1987]. In the current version it is a model for a closed economy. It roughly captures the main features of the German public pension system and mainly serves as a tool to investigate the long-run effects of the demographic change on the pension system, major macroeconomic variables and the welfare of different generations. These effects are considered under the current rules of the public pension system as well as under reform options for the pension system debated in Germany.

The parameters of the utility and the production function were set to plausible values and are similar to those used in comparable studies. Although, some important endogenous variables like the interest rate take realistic values, the results should be interpreted as an illustration of the effects of policy changes, but not as precise forecasts.

\footnotetext{
12 For a detailed description of the model as well as an application to the German pension fund system see Buslei [1997] and Buslei and Kraus [1996].
} 
The model is dynamic in the sense that some exogenous variables change over time, for example birth rates and survival probabilities, and the agents react to these changes. However, for the present purpose the birth rates and the survival probabilities are held constant to keep the model simple and to simplify the comparison of the results with the other models considered, which do not incorporate demographic changes.

\section{Special characteristics of the model}

The agents in the model are representative individuals who differ in age, a representative firm and the government. Individuals maximize an intertemporal utility function with consumption and leisure as the arguments subject to an intertemporal budget constraint. They are assumed to have perfect foresight. Individuals enter the model at age 21. Although individual lifetime is uncertain, the maximum age is 100 . Death probabilities were calculated on the basis of tables delivered by the German Statistical Office for the year 1992. Capital markets are assumed to be perfect and individuals hold all their assets in (fair) annuities which implies that bequests are excluded. Although this assumption is surely restrictive and should be abandoned in an extended version of the model, it should hardly affect the difference in the labor supply that results from the policy change considered in this study. Over the life cycle individuals experience different labor productivities. The productivity increases when individuals are young, reaches a maximum at about age 45 and falls subsequently.

The representative firm behaves competitively and maximizes profits given a Cobb-Douglas technology with labor and capital as inputs. The depreciation rate is set exogenously at the long term average value in Germany.

Government consumption was set exogeneously at a fixed amount per capita and does not enter the utility functions of the individuals. The rate of the capital income tax was set at $20 \%$ and the rate of the excise tax at $15 \%$. The revenue of these taxes and the income tax (tax on wage income) is used to finance government consumption. The endogeneously determined wage tax rate is about $22 \%$ in the benchmark equilibrium ${ }^{13}$.

The government also rules a pension system on a pay-as-you-go basis. Simplifying, the rules of the German pension system prior to 1999 were modeled as follows: Individuals aged 61 and over are eligible for pension transfers. The level of the pension depends on wage income prior to pension eligibility in the following way: The wage income of a generation is set in relation to the mean wage income in each year prior to retirement. These relations are summed up and the result is multiplied by a value called current pension value (,,aktueller Rentenwert"). The current pension value is identical for all pensioners in a year, but is adjusted to changes in mean net labor income each year. The starting value for the current pension value was set exogenously. The resulting replacement ratio is about $62 \%$. Simplifying, it is assumed that individuals consider their contributions to the pension system as taxes and do not take into account that the level of their pensions depends on their labor income.

Pensioners may supply labor while receiving a pension. This is contrary to some similar models in which labor supply is set to zero when individuals are eligible for pensions. But three assumptions in this model imply that individuals only supply a negligible amount of labor while receiving a pension. Firstly, utility of leisure is assumed to rise sharply in the old age and se-

\footnotetext{
13 This value is somewhat higher than the ratio of the total wage tax and gross labor income which for example in 1996 was about $18 \%$. The deviation should not alter the results considerably.
} 
condly, productivity declines in the old age, as was already mentioned. Thirdly, it is assumed that an additional tax falls on the wage income of individuals of age 61 to 64. This tax should be considered as a proxy for the legal restriction that labor income may not exceed certain limits for the time being early retired.

As the labor and the goods markets are perfectly competitive, markets clear and (unvoluntary) unemployment does not exist. Thus, employment effects of policy changes mainly result from changes in labor supply.

\section{Model results}

The model delivers the equilibrium values for each year in the period under consideration. Among these variables are output, consumption, interest rate, wage and the contribution rate to the public pension system. Moreover, the equilibrium values of the life cycle plans for consumption, savings and labor supply result for each cohort. Based on these values, life time utility of each cohort can easily be calculated.

\section{Strengths and weaknesses of the model, possible extensions}

An important strength of the model is that it points to the possibly important effects of the age distribution on the result of policy changes. For example, raising the excise tax to finance part of the pensions hurts the currently old, while it might be advantageous for all in the long run. The current version should be extended in several directions. For example, it should not be assumed that all assets are held in annuities. This would also allow to consider bequests. Furthermore, determining the parts of assets held in annuities and in other assets endogenously would contribute to a more realistic description of what we observe. Moreover, not the whole contributions to the pension system should be considered as taxes because there is a relationship between contributions and the level of pensions in the German pension system.

Perhaps the most important weakness of the model in the context of the policy investigated here is that unemployment is not included in the model. It is intended to overcome this shortcoming in a following version that additionally covers union behavior (see Jensen [1997] for such an approach for the case of Denmark).

\section{A Small Reduced Form Model for the German Labor Market}

\section{General characteristics of the model}

The next model we consider was developed by Steiner [1998] to analyze the employment and wage effects of social security financing and was thought as a cross check to the corresponding results of the OECD Jobs Study [1994] for West Germany. For this reason the model was developed in close connection to the work of Tyrväinen [1995a,b]. The model consists of two equations - a wage equation and a demand for labor equation. Based on annual data for West Germany from 1960 to 1995 the model simulates the wage and employment effects due to a cut in the social security contribution rates and its financing by an increase in indirect taxes. The model distinguishes between short- and long-run effects. In the short-run the model allows a certain degree of disequilibrium which is modelled by an error-correction approach, whereas the cointegration regression delivers the corresponding long-run relationship.

The time horizon of the model is short- to medium term, but nevertheless also long-run relationships of economic policy activities can be analyzed properly by simulating the model over a 
long-term horizon of around ten years. The model considers a closed economy, and within this economy emphasis is put on the labor market only. For this reason the small macro model does not contain an explicit model closure rule.

\section{Special features of the model}

All assumptions about the behavior of economic agents are given implicitly in the sense that the equations to be estimated are compatible with standard optimization behavior of economic agents under perfect foresight. In this sense the demand for labor may be derived from a cost minimizing behavior of a representative enterprise, which make labor demand depended on the real wage, output, productivity and the employers' social security contribution rate. The wage equation can be derived under the hypothesis of collective bargaining. For the wage behavior it is assumed that employees (unions) view the employees' contribution rate like direct taxes, but do not take the employers' contribution rate into account. This is a maintained assumption of the model which cannot be tested.

An empirically testable hypothesis is that the elasticity of contract wages with respect to prices is one in the long-run, i.e. the long-run Phillips curve is vertical. Furthermore, increases in indirect taxes are fully transmitted into higher contract wages, i.e. unions do not seem to distinguish between price increases resulting from higher indirect taxes and other factors, respectively. Except for the output variable in the demand for labor equation no links to other markets are directly modelled.

\section{Model strengths and weaknesses, possible extensions}

The model can be handled in a simple manner and delivers an explanation of the wage setting behavior in West Germany and the corresponding demand for labor. Weaknesses of this approach are partly due to econometric problems such as multicollinearity which prevent differentiation between employers' and employees' contribution rates, and due to data availability which prevent a richer specification of the corresponding equations at the macro level. Model extension might consist of including a labor supply equation as well as of taking the response of other markets into account, e.g. by integrating an output - price - equation. Using an Okuntype relationship the model can easily be extended to include the goods markets as well.

\section{The European Tax Analyzer (ETA)}

\section{General characteristics of the model}

The European Tax Analyzer ${ }^{14}$ is a co-development of the ZEW and the University of Mannheim (Department of Business Economics). It is a partial model of typical corporations in the industrial sector of an economy. The primary goal of the ETA is an international comparison of the effective tax burden, taking all relevant firm specific taxes and surcharges into account. The model allows to compare the tax burden for German, French, British, Dutch, and U.S. enterprises. To obtain comparable results across countries as well as across firms with different characteristics, for example different depreciation allowances or the number of persons employed, the comparison is made on the basis of the effective instead of the marginal tax burden.

The ETA is a static model which does not have a calendar time dimension, but it allows to calculate the impacts of changes in the system for different time periods. The maximum time

\footnotetext{
${ }^{14}$ See Jacobs and Spengel [1996] and Jacobs, Spengel, Gröschel, Krahmer, Schmidt and Wünsche [1996] for a detailed description of the European Tax Analyzer.
} 
horizon amounts to ten periods. Furthermore, the ETA is capable to take account of the fact that firms may have domestic and foreign subsidiaries and pay their dax duties in the country where the profits are originated, i.e. it is possible to analyze multinational firm strategies - in this sense the ETA is a model of an open economy.

The ETA uses data from annual balance sheets and profit and loss accounts. For Germany the data inputs are taken from the Deutsche Bundesbank and the Hoppenstedt data bank. The latter is used for data on employment and $R \& D$ activities to distinguish between firm size and $\mathrm{R} \& \mathrm{D}$ performers in calculating the effective tax burden.

The determination of the firm's effective tax burden proceeds in five steps. First, based on the principles of firms' investment calculus the Tax Analyzer determines the amount of wealth $W$ at the end of period 0 of the typical firm. This amount is equivalent to the total value of equity $E$ (only ordinary shares issued) before tax and other duties. Second, the first step is repeated for period 10. Third, the effective yield $r$ before tax and duties is given by the discounted ratio of the firm's wealth $W$ in period 10 to the equity $E$ in period 0 minus 1 .

$$
r=\left[\frac{W_{t}}{E_{0}}\right]^{\frac{1}{t}}-1
$$

Fourth, the effective yield $r_{t d}$ after taxes and duties is calculated in the same way. Finally, the effective tax burden ETB is given by the relative deviation of $r_{t d}$ from $r$.

$$
E T B=\frac{r-r_{t d}}{r}
$$

The model is simulated under the assumption of unchanging employment and constant capital stock.

Special features of the model

The ETA considers typical enterprises which produce one good. Although no production function is explicitly incorporated in the model it is assumed that the typical firm maximizes profits. Due to the primarily goal of the program the private sector as well as the public sector are treated as exogenous. Also, given that a typical firm is considered, prices are taken as given for the enterprise. With respect to the labor market the ETA allows to distinguish between three types of labor with the corresponding wage rates. Although some labor market data are used there is no direct link to calculate possible labor market effects due to changes in tax rates. With respect to the capital market the ETA distinguishes four different interest rates on deposits which are treated as exogenous.

The European Tax Analyzer is also capable to compare the effective tax burden for different types of enterprises: differences are allowed with respect to the number of employees as well as with respect to whether a firm can be charcterized as R\&D-performer or not. Usually, R\&D-intensive firms are considered as highly occupational intensive. These distinctions allow to analyze additionally the different tax burden of differently structured enterprises.

\section{Model results}

As output the ETA delivers the effective tax burden of a typical firm in the industrial sector for the countries investigated.

Model strengths and weaknesses, possible extensions 
With respect to the simulations the European Tax Analyzer cannot account for any financing due to the implicit model assumption that indirect taxes are passed fully on prices. A second limitation of the Tax Analyzer in the present context relates to the behavior of the firm due to a reduced tax burden. The analysis of the model stops when the new effective tax burden is calculated. Therefore, possible managerial decisions due to a reduced tax burden is based on plausibility assumptions.

Extensions of the ETA consist in enlarging the number of countries analyzed as well as in using the Analyzer for regional specific tax burden comparisons. New research activities relate to the behavioral determination of investment due to tax changes and the effects of an ecological taxsystem. With respect to these activities new firms from non-industrial sectors (i.e. services) were added and first computations have been performed.

\section{Design of the Simulation Study}

The experiment we carry out consists of a four percentage points' reduction of the contribution rates to the social security system of currently around 42 per cent of the gross wage income. This reduction applies only to those models in which employers' as well as employees' contribution rates are considered. For those models which only contain the contribution rate of employers or employees, respectively, the reduction amounts to two percentage points. Furthermore, we do not distinguish between different types of social security insurances, but instead look at the contributions as a whole. To compensate for the reduced receipts, the government increases indirect taxes simultaneously in such a way that the reduced receipts are fully compensated by the increased tax revenue in the first year or time period in which the modification takes place. For the remaining years or time periods no such settlement is assumed. ${ }^{15}$

Before turning to the results some additional remarks have to be made with respect to the simulations in the five models. Because of the restriction to West Germany as well as the limited time period the simulations with the Konstanz Disequilibrium Model had to be carried out for earlier periods. Therefore, qualitative statements, and not forecasts about the recent impact of such measures are given. With respect to the different regimes and their expected influences the policy measure was carried out during a period characterized by a strong goods demand regime (1982 - 1984) and a period characterized by a strong capacity regime (1988 - 1990).

Another point relates to the treatment of indirect taxes in the simulations. The models are different with respect to the modelling of indirect taxes. In some models (GEM-E3 model, Konstanz Disequilibrium Model and the European Tax Analyzer) indirect taxes are splitted into its components, whereas in the other models indirect taxes are considered as a whole (OLG model, LM). In the latter case counter-financing proceeds via an increase in indirect taxes, and in the former case the value-added tax rate is increased to such a level that the cut in the contribution rate is neutral with respect to the general government budget. As already mentioned in

\footnotetext{
15 This assumption deviates from the one in Franz, Göggelmann and Winker [1997], who assume a neutral counter-financing over the whole simulation period. But as these authors remark, this assumption implies that on a yearly base indirect tax rates have to be adjusted in order to meet the needs of a settled budget. The reason for this assumption was to avoid a mixture of the counter-financing of tax financing, government expenditure cuts and/or by borrowing. Given the assumption, we cannot be sure that the additional indirect tax receipts will equal the revenue losses due to the reduction in each year.
} 
the foregoing part of the paper, no counter-financing is considered for the European Tax Analyzer.

Another distinction refers to the simulation periods. In the Konstanz Disequilibrium Model two simulation periods are chosen. The European Tax Analyzer does not have an explicit calendar time dimension; instead the Tax Analyzer starts from period 0 and simulates the effects for the next ten periods. These periods are not necessarily quarters or years. Therefore, some care should be given when comparing the simulation results over time. The intertemporal overlapping generation model uses the time span up to 2040 as its reference period.

Finally, due to the characteristics of the calibration models as well as the European Tax Analyzer, these models do not suffer from the German unification in 1990, but the Konstanz Disequilibrium and the labor market model do. Required data for updates of the models are no longer available as a complete data set. Therefore, the results of the models only apply to West Germany. Transmitting the quantitative simulation results for Germany as a whole may be misleading. But this does not mean that the qualitative results in any case will not apply for the whole of Germany.

\section{Results of the Simulation Studies for the Different Models}

The presentation of the results starts wirth the two most general models - the GEM-E3-model and the Konstanz disequilibrium model. The simulation with the GEM-E3-model was carried out for two different labor market specifications. The first specification assumes a perfect, neoclassical labor market whereas the second specification builts in some imperfections. These alternative assumptions were made to check for a possible sensitivity of the simulation results due to different market clearing mechanisms. In the neoclassical specification of the GEM-E3model, the real wage rate is fully flexible and market clearing is assumed which implies that no involuntary unemployment arises. The revenue-neutral reduction of the social security rate requires an increase in the value-added tax rate by 4.14 percentage points. In the imperfect labor market regime of the GEM-E3-model the real wage rate is kept constant. The nominal wage rate covers inflationary effects, i.e. it changes according to the consumer price index. Obviously, effects differ only slightly from the impacts observed in the neoclassical specification. In the imperfect labor market version revenue-neutrality requires an increase in the valueadded tax rate by 4.15 percentage points, as can be seen from Table 2 . In both versions there is an increase in employment three years after the cut of $0.71 \%$ in the neoclassical version and of $0.64 \%$ in the sticky wage version, respectively.

As with the GEM-E3-model two different simulations were run in the Konstanz disequilibrium model depending on the regime prevailing in the economy. In both regimes, the demand as well as the capacity regime, a reduction of the contribution rate leads to small employment effects in the private sector. Comparing both regimes, the employment effect with an increase of $0.25 \%$ relative to the base line is larger in the demand regime (lasting from 1982 - 1984) than in the capacity regime, where employment only increases by $0.07 \%$, see Table 2 . The reason for this outcome is that an economy being in the supply regime is constraint by the existing capacity. In such a situation a reduction of unit labor costs will only have minor employment effects. Extending the existing capacity takes too much time to be able to satisfy the additional demand in the short run. 
The positive employment effects result from two independent sources. The first reason is that due to the increase in real disposable income the demand for goods - consumption as well as investment - rises. The second argument comes from the capital-labor-substitution due to lower unit labor costs.

Compared with the GEM-E3-results the employment effects in the Konstanz disequilibrium model are considerably smaller in magnitude. Still minor effects are obtained in the overlapping generations model. As a first attempt to a complete sensitivity analysis, the results were calculated for two different values of the intratemporal elasticity of substitution ( IRS). Three years after the cut in the social security rate, employment has risen by only $0.09 \%$ in the case of an IRS of 0.8 - which is the usually value in this kind of models - or even less $(0.03 \%)$ for an IRS of 0.5. To run the simulation under comparable conditions the rate of the excise tax increased from $15 \%$ to about $19.24 \%$ in both cases. In the benchmark equilibria the revenue of about 4.24 percentage points of the excise tax equals in both cases the revenue of 4 percentage points of the contribution rate to the pension system. The additional revenue from the excise tax is entirely used to subsidize the pension system. Because of this subsidy, the endogenously determined contribution rate to the pension system falls. As this results in higher net wages, the pension value increases. This increase explains why in the new long-run equilibrium the reduction in the contribution rate caused by the increase in the rate of the excise tax by 4.24 percentage points amounts to ,only“ about 3.4 percentage points in both cases.

The employment effects of the policy change are rather small in both cases. Note that the results for the higher value of the IRS are by and large in line with those of Fehr [1997] who considers a reduction in the contribution rate by about two percentage points in a similar model and chooses a value for the IRS of 0.8 . It should moreover be noted that the results depend partly on the assumptions made with respect to the labor supply of retired people. These assumptions about the preferences for leisure and the productivity in old age imply that a policy like the one considered here does not result in a substantially higher labor supply of the retired individuals although the increase of the rate of the excise tax reduces their real income. It is an empirical question how elastically labor supply of retired people reacts to changes in income. To our knowledge this question is still unsolved. Thus, in reality the short-run increase of labor supply might be slightly higher in reality than in the model. Note that the change in employment does not necessarily mean that more individuals are employed. What changes are the hours worked. This is a logical consequence of the absence of unemployment in the model.

The two equations labor market model - the wage equation and the demand for labor - are dynamically simulated starting in 1970. As in the Konstanz disequilibrium model, the results apply to West Germany only. But contrary to the Konstanz model the labor market model is based on annual data. The simulation was only performed for the employment equation and the cut in the contribution rate was two percentage points because only the employer's side is considered. Based on these assumptions the model predicts a $0.50 \%$ increase in employment three years after the cut.

Finally, we turn to the results of the European Tax Analyzer which are given in Table 3. Because the Tax Analyzer is a firm specific instrument only the employers' payments to the social security system are taken into account. We calculated a reduction of two percentage points for the pension insurance. The specific model assumption does not allow a compensation through indirect taxes. It is assumed instead that increasing indirect taxes are fully shifted to the consumers. Furthermore, the firms do not react to the decreasing labor costs. 


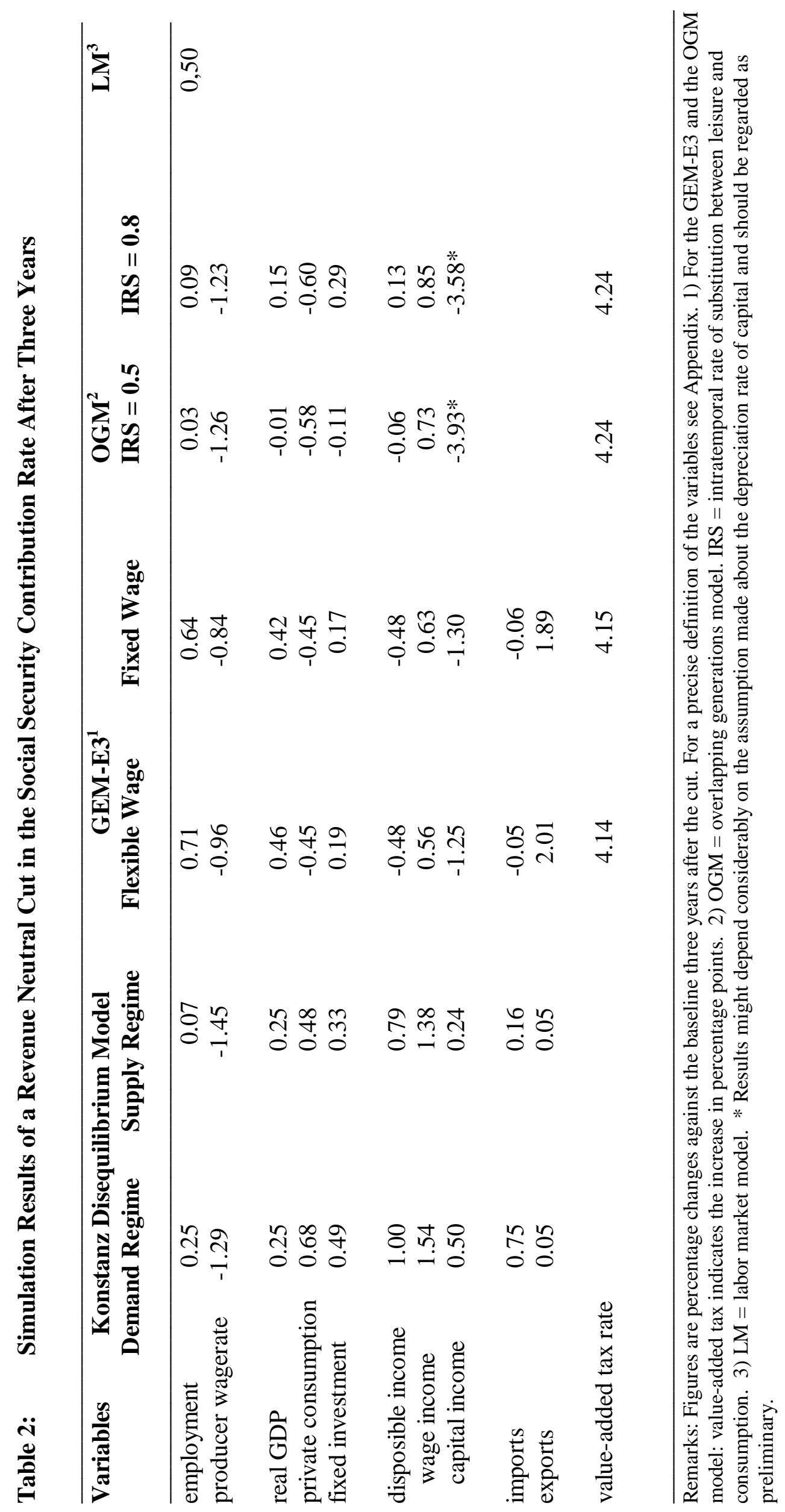


The reduction in social security contributions leads to decreasing effective tax burden for all seven types of firms analyzed in the simulation study. The lowering of the social expenditures for the employer reduces the labor costs. Assuming constant employment, the firms' taxable profits increase. The effect of decreasing labor expenditures is for all firms larger than the effect on profits. This in turn leads to a reduction of the effective tax burden. In employment intensive sectors ${ }^{16}$ the reduction is clearly higher than in the other sectors which are mostly capital intensive.

Table 3: Effects of a Cut in the Social Security Contribution Rate: The European Tax Analyzer

\begin{tabular}{lllll}
\hline \multicolumn{4}{c}{ Percentage Change of } \\
& $\begin{array}{l}\text { effective } \\
\text { overall } \\
\text { burden }\end{array}$ & labor costs & $\begin{array}{l}\text { profits before Cash-Flow } \\
\text { taxes }\end{array}$ & \\
\hline Standard & -3.46 & -1.44 & 6.28 & 1.70 \\
10000 HT & -2.48 & -1.42 & 26.42 & 5.25 \\
10000 LT & -3.12 & -1.53 & 8.41 & 1.60 \\
1000 HT & -4.36 & -1.52 & 12.10 & 2.36 \\
1000 LT & -3.05 & -1.51 & 6.00 & 1.41 \\
200 HT & -4.06 & -1.52 & 5.22 & 2.44 \\
200 LT & -3.16 & -1.64 & 6.97 & 1.51 \\
\hline
\end{tabular}

1) Including taxes and expenditures to the social security system.

Standard means the average enterprise in the industrial sector; HT $=$ high technology enterprises, LT $=$ low technology enterprises. The figures before HT/LT refer to the number of employees.

The employment effect is derived in an indirect way because the Tax Analyzer is not capable to quantify the amount of additional employment due to reductions in the effective tax burden. But theoretical considerations on firms' behavior lead to positive employment effects. The primary effect is based on the reduced labor costs. The decreasing relative labor to capital price enables firms to demand more employment. The secondary effect is the cash-flow effect. From a theoretical point of view ${ }^{17}$ as well as from some recent empirical investigations ${ }^{18}$ analyzing the relationship between cash-flow and investment activity, additional cash-flow leads to an increase in investments in fixed assets. The larger capital stock then requires a higher level of

\footnotetext{
${ }^{16}$ In the industrial sector mostly the R\&D performer (chemical or electronic sector) are characterized as employment intensive. Capital intensive firms are in low tech sectors like food or wood industries.

${ }_{17}$ Myers / Majluf [1984] and Myers [1984] point to a causal relationship between asymmetric information and internal finance.

${ }^{18}$ See e.g. Bond / Harhoff / v. Reenen [1998].
} 
employment. The cash-flow elasticities and magnitudes of employment effects are different between different types of firms (with respect to size and R\&D activities). This kind of employment effect was not calculated because there is still a gap between the micro and macroeconomic models.

To summarize the results of this section all models which explicitly deal with employment indicate that a revenue neutral cut in the social security contribution rate will lead to some positive employment effects in the short to medium run. But the size of the employment effects differ considerably among the models on one hand, and they differ also within a model when different regimes are considered. The employment effects are highest in the GEM-E3-model and lowest in the overlapping generations models. For the Konstanz disequilibrium and the labor market model the effects are half of a percentage point or even lower. These qualitatively similar results are encouraging if one takes into account the different purposes the models have been built for. Nevertheless, some of the discrepancies may be attributed to different transmission mechanisms of the models. Therefore, in the final part we discuss some possible explanations which may account for this outcome. For the remaining discussion we restrict ourselves to the GEM-E3-, the Konstanz- and the overlapping generations models.

\section{Discussion of the Results and Conclusions}

In the preceding section we presented the simulation results of a revenue neutral cut with respect to employment. Although all models indicate an increase in employment due to a cut in the social security contribution rate, the effects differ markedly in size. In this section we offer some explanations for these results. Furthermore we discuss an additional topic, namely that despite of the unique employment results the underlying transmission mechanisms as well as the theoretical foundations of the models are quite distinct and may account for the numerical differences. Another argument for the reported quantitative differences might be due to the different definitions of the variables used in the models. In the appendix we therefore, give a detailled description of the variables of Table 2 .

As mentioned in the second section of the paper none of the models considered is completely identical with respect to the modelling of the social security contributions. The GEM-E3model and the Konstanz disequilibrium model consider both parts - the employers' and the employees' contribution rates to the social security system as a whole, whereas the overlapping generations model only captures the contribution rate to the pension fund. The labor market model restricts itself to the contribution rate of the employers, and so does the European Tax Analyzer. Although we accounted for these differences by appropiately correcting the cuts, differences in the results may nevertheless be partly attributed to these model features. The omission of certain markets or the restriction to look at only one side of a market implies that possible feedback effects between different markets or between demand and supply within a single market are not accounted for. This may be a potential source for the numerical differences in the simulations.

Increasing the rates of total indirect taxes or the value-added tax may also be a possible source of divergence. Economic agents cannot avoid the value-added tax, but they clearly can avoid other indirect taxes by appropiately substituting lower taxed goods for higher taxed ones. Taxes on tobacco products or beveridges as well as on luxury goods may serve as an example. Therefore, individuals may be hit differently - and thus respond differently - by either increasing 
indirect tax rates or the rate on value-added tax. This may especially be the case for individuals with low income. These arguments may also partly contribute to the numerical differences of the simulations.

In our opinion the degree of aggregation or disaggregation of the models seems to be of minor importance. In the highly disaggregated GEM-E3-model the employment effects are both larger than in the highly aggregated labor market model, which again is higher than in the Konstanz disequilibrium model. Thus, the simulation results do not show any systematic differences which might be attributed to different levels of aggregation. Also the different time horizons of the models do not seem to have a significant impact on the results if the three years period after the cut is considered. But it should be mentioned that in the overlapping generations model the employment effect becomes negative in the long run.

These arguments suggest that alternative assumptions of the underlying behavior of economic agents could be a source of the numerical differences. At a first glance the simulation results with the GEM-E3-model seem to contradict this presumption. Regardless of the wage specification - and thus of the underlying theoretical justification - the numerical results differ only slightly with no clear patterns in favor of one of the alternatives. A possible explanation for this outcome is the assumed low elasticity of labor supply (0.1), which implies that even in a flexible wage model the response to changes in the wage rate is rather inelastic.

Major differences of the results in dependence of the regime have to be reported for employment and imports in the Konstanz disequilibrium model. If the economy is in a demand regime the employment effects of a cut are more than three times larger than in a supply regime. Given that the demand regime is characterized by unvoluntary unemployment and low capacity utilization rate, an increase in real disposable income leads to a higher aggregate demand which will be satisfied by raising the capacity utilization rate, and by increasing the demand for labor. On the other hand, if the economy is in a capacity regime, i.e. fully employed capacities, no additional employment can be realized in the short run. Furthermore, additional aggregate demand can only partly be satisfied from domestic sources. Therefore, domestic production will increase only slightly so that part of the additional demand will lead to an increase in imports. But these considerations do not necessarily imply that import growth must be higher in a supply than in a demand regime. In a demand regime an increase in aggregate demand improves the capacity utilization rate which is accompanied by higher imports of goods and services.

The stronger increase in imports in the demand regime may also help to explain why real GDP growth is identical in both regime although the employment effects are different. In both regimes exports increase by $0.05 \%$, but import growth differs. Therefore, in the demand regime the expansionary effect on real GDP is somewhat dampened. In the present case the equality of both rates is by pure chance. The changes in the other variables listed in Table 2 show that the effect of the cut are usually stronger in the demand than in the supply regime, although the differences are not so pronounced as they are for employment.

Within a special model the findings - different wage assumptions and alternative regimes - suggest that certain kinds of imperfections and alternative states of an economy do not lead to qualitatively different results in the models' outcomes.

But things are slightly more sophisticated between the Konstanz and the GEM-E3-model and the overlapping generations model as well, whereas a comparison between the GEM-E3- and the overlapping generations models reveals a higher degree of correspondence. Ignoring numerical differences the three models uniquely predict an increase in GDP and labor income as well 
as in fixed investment, but opposite effects in real private consumption, real disposable income and imports (the GEM-E3- and the Konstanz model only). Although for both models wage income increases, capital income declines in the GEM-E3-model to an extend that disposable income declines as a whole. In the Konstanz model capital income increases and thus strengthens the effect on total income. In the latter, the cut in the contribution rate leads to a reduction of the firms' wage bill. Although real labor income increases, real disposable income declines in the short run. This decline results from an overcompensating effect of a lower capital income. But this short run effect vanishes quickly. Three years after the cut both types of income have increased with real labor income stronger than capital income.

The decline in capital income in the GEM-E3 model results from a decline in the demand for capital goods which follows from substituting capital for labor due to lower labor costs. The reduced capital demand causes the ex post shadow price of capital, the market clearing price for a period, also to decline (putty-clay specified production function). In the model real capital income is defined as the product of the shadow price of capital and the (temporary fixed) capital stock deflated by the consumer price index. As consumer prices increase and the shadow jprice of capital decreases, there is an unambigious pressure on real capital income to decline. The current jperiod investment demand depends positively on the shadow price of capital, the depreciation rate and (also positively) on expected output. The expectation about future output is driven by the current output (myopic expectations). The latter increases even though domestic demand falls. The reason can be found in the rise of export demand: As factor taxes are replaced by indirect taxes, export prices decrease. This shift of tax burden stimulates export demand which overcompensated the negative impact on private consumption. Hence, both production and GDP increase. As the output effect dominates the price effect in the investment decision, investment demand rises as well.

In the Konstanz model capital income is defined in terms of the national accounting system which means that both income variables are not comparable. The increase in capital income in the Konstanz model is the result of lower labor costs on one hand and of the increase in GDP on the other.

Another point to be mentioned relates to the different movements in real private consumption in both models. In the Konstanz model employment as well as real disposable rises with the latter variable being one of the explanatory variables in the consumption function. Therefore, an increase in real disposable income leads to an increase in private consumption.

In the GEM-E3-model private consumption also depends on real disposable income. For the reasons mentioned above the GEM-E3-model predicts a decline in disposable income. Therefore, real private consumption also declines.

For the OLG- model the decline in private consumption results from different sources. First of all, the cut in the social security rate affects only those who are currently working. Retired people do not gain from the cut, instead they are adversely affected in their real disposable income due to the higher indirect tax rate which lowers the quantity of goods they demand for consumption. The second effect stems from those who are currently working because they anticipate that at the time they will retire their consumption level will be lower than planned. For this reason they, too, reduce current period consumption and increase savings. The third effect results from the lower interest rate relative to the baseline period. The decline in the interest rate is a response to the increase in saving. A lower interest rate stimulates current period consumption. But this effect is too small to overtune both forementioned effects. 
The lower interest rate stimulates the demand for investment goods which immediately leads to a higher capital stock. To employ this higher capital stock efficiently employers demand for more labor. Both effects - a higher capital stock as well as increased employment - lead to a higher output level.

What conclusions can be drawn with respect to employment from the results? First, all models analyzed in the paper indicate the same qualitative result of a revenue neutral cut of the contribution rate to the social security system. Quantatively the results are quite different in magnitude. This suggests that from a qualitative point of view differences in the various models are of less importance than from a quantitative point of view. Secondly, but care must be taken even from a qualitative point of view if more variables are considered than employment alone. Although within a model different assumptions about regimes or imperfections have a minor impact on the results, differences among the models are considerable. Most of these differences can be attributed to alternative model building philosophies. Thirdly, contrary to these findings different time horizons or different degrees of aggregation do not seem to have a significant impact on the results, at least qualitatively.

But when interpreting the results one should keep in mind that each model was and is designed for certain policy applications. Therefore, if the main interest is in learning something about the effects of labor demand, a neoclassical model of the labor market will not be well suited for this purpose. If instead labor supply behavior is the topic of interest, the Konstanz macroeconomic disequilibrium model will be of limited use because labor supply effects are not captured by the model.

Finally, from an economic policy point of view the results of the models do not suggest that a revenue neutral cut in the social security contribution rate will lead to a considerable improvement of the present (un-)employment situation. With about 28 million employees and around 4 million unemployed the cut will lead to an additional employment after three years of around 200,000 people in the most favorable case - the GEM-E3-model with flexible wages - and of around 70,000 additional employees in the Konstanz model. If the overlapping generations model is used, only 7,000 people will find additional employment. Furthermore, there is no guarantee that this additional employment will lead to a reduction in unemployment of the same order. These rather disillusioning figures call for additional and accompanying policy actions by the political authorities if unemployment should be reduced to a considerable amount. This the more if one keeps in mind that the simulated reduction of the contribution rate is of a size which is unlikely to appear in practical policy as a one step action.

Comparing different macro models for some common policy action proofed to be a valuable exercise for a better understanding of the underlying working mechanisms of the models. Usually, different models produce different results. Therefore, we suggest further model comparisons in the future. This seems the more necessary the more problems will arise in the near future. Nearly all nationally oriented macro models have to be reconstructed in Europe to account for the European Monetary Union in 1999. Lacking a sufficient amount of data time series econometrics will run into serious problems. Therefore, to deal with this new situation in Europe and to provide the public further with latest research results, empirically oriented macro economists should use various models and model building approaches and discuss the outcomes carefully. 
A second argument why different models should be taken into account when providing information to the public stems from the differences between reality and model building. Usually models are constructed on a sound theoretical base; but reality is rarely so clear-cut as theory suggests. Therefore, discussing different results due to different theoretical assumptions may help to improve our own understanding of the working of an market economy as well as the quality of economic policy decisions. 


\section{Appendix}

\section{Description of data}

a) GEM-E3-Modell

employment

producer wage rate (after tax)

real GDP

private consumption

fixed investment

disposable income

wage income

capital income

imports

exports total employment in private and public sector, national accounting definition

real equilibrim wage rate including employers' social security contribution rate, deflated by GDP-deflator real gross domestic product with public sector included, national accounting definition

real, national accounting definition

real fixed total investment

real, deflated by private consumption deflator, private sector, national accounting definition

net wage and salary income after taxes, deflated by priva te consumption deflator, private sector, national accounting definition

net income from providing capital (interest payments) after taxes, deflated by private consumption deflator, private sector, national accounting definition real, imports of goods and services, national accounting definition

real, exports of goods and services, national accounting definition

\section{b) Konstanz Disequilibrium Model}

employment

producer wage

GDP-

real GDP

private consumption

fixed investment

disposable income

wage income employment in the private sector, national accounting definition

gross labor income, private sector, deflated with deflator, national accounting definition

real gross domestic product with public sector excluded, national accounting definition

real, national accounting definition

real gross fixed investment, private sector, without house rental, national accounting definition real, deflated by private consumption deflator, national accounting definition net wage and salary income, deflated by private consumption deflator, private sector, national accounting definition 
capital income

imports

exports net income from entrepreneurship and wealth, deflated by private consumption deflator, national accounting definition real, without raw-materials and without semi-final goods, national accounting definition

real, exports of goods and services, national accounting definition

\section{c) Overlapping Generations Model}

employment

real GDP

private consumption

fixed investment

disposable income

producer wage

tion rate

\section{d) Labor Market Model}

employment hours worked

real gross domestic product with public sector included

real, deflated by implicit model price index of the consumption good

in current prices

real, wage income plus interest earnings plus pension transfers

wage rate including employers' security contribu-

total employment, national accounting system definition 


\section{Literature}

Auerbach A. J. and Kotlikoff L. J., [1987]: Dynamic Fiscal Policy. Cambridge et. al.

Bond S.; Harhoff D. and v. Reenen J., [1998]: Investment, R\&D and Financial Constraints in Britain and Germany. mimeo, Mannheim.

Bovenberg A. L. and Goulder L. H., [1996]: Optimal Environmental Taxation in the Presence of Other Taxes: General Equilibrium Analysis. American Economic Review, Vol. 86, $985-1000$.

Bovenberg A. L. and de Mooij R. A., [1994 a]: Environmental Levies and Distortionary Taxation. American Economic Review, Vol. 84, 1085 - 1089.

Bovenberg A. L. and de Mooij R. A., [1994 b]: Environmental Taxes and Labor-Market Distortion. European Journal of Political Economy, Vol. 10, 665 - 683.

Bowden R. J., [1978]: The Econometrics of Disequilibrium. Studies in Mathematical and Managerial Economics, Vol. 26, Amsterdam, New York und Oxford.

Buslei H., [1997]: Übergang auf ein niedrigeres Rentenniveau. In: Wirtschaftspolitische Blätter, 3-4, 294 - 304.

Buslei, H. and Kraus F., [1996]: Wohlfahrtseffekte eines graduellen Übergangs auf ein niedrigeres Rentenniveau. In: Steiner V. and Zimmermann K. F. (eds.): Soziale Sicherung und Arbeitsmarkt - Empirische Analyse und Reformansätze, ZEW-Wirtschaftsanalysen, Band 6, Baden-Baden, 57 - 91.

Capros P; Karadeloglou P. and Mentzas G., [1990]: An Empirical Assessment of Macroeconometric and CGE Approaches in Policy Modeling. Journal of Policy Modeling, Vol. 12(3), 557-585.

Capros P.; Georgakopoulos T.; Van Regemorter D.; Proost S.; Schmidt T. and Conrad K., [1997]: The GEM-E3 General Equilibrium Model for the European Union. Economic \& Financial Modelling. Special Double Issue. Summer/Autumn, Vol. 4, No. 2\&3, 51 - 160.

Conrad K. and Schmidt T. F. N., [1997]: Double Dividend of Climate Protection and the Role of International Policy Coordination in the EU - An Applied General Equilibrium Analysis with the GEM-E3 Model. ZEW Discussion Paper No. 97-26, Mannheim.

Drèze J. H. and Bean Ch. R., (eds.), [1990]: Europe's Unemployment Problem. The MIT Press, Cambridge, Mass.

Entorf H.; König H. and Pohlmeier W., [1992]: Labour Utilization and Nonwage Labour Costs in a Disequilibrium Macro Framework. Scandinavian Journal of Economics, Vol. 94, 71 $-83$.

Fair R. C. and Jaffee D. M., [1972]: Methods of Estimation for Markets in Disequilibrium. Econometrica, Vol. 60, 1972, pp. 497-514.

Fehr, H., [1997]: Belastungswirkungen der aktuellen Reformvorschläge zur Einkommensbesteuerung und zur Alterssicherung. Tübinger Diskussionsbeiträge Nr. 101, Wirtschaftswissenschaftliche Fakultät der Eberhard-Karls-Universität Tübingen, Tübingen.

Fehr H. and Wiegard W., [1996]: Numerische Gleichgewichtsmodelle: Grundstruktur, Anwendungen und Erkenntnisgehalt. In: Ökonomie und Gesellschaft, Jahrbuch 13: Experimente in der Ökonomie, Frankfurt (M.), 296 - 339.

Franz W.; Göggelmann K.; Schellhorn M. and Winker P., [1998]: Quasi-Monte Carlo Methods in Stochastic Simulations - An Application to Fiscal Policy Simulations using an Aggregate Disequilibrium Model of the West German Economy 1960 - 1994. ZEW- Discussion paper 98-03, Mannheim. 
Franz W.; Göggelmann K. and Winker P., [1997]: Einige Wirkungen von steuerlichen Umfinanzierungsmaßnahmen in einem makroökonometrischen Ungleichgewichtsmodell für die westdeutsche Volkswirtschaft. ZEW Discussion Papers No. 97-19, Mannheim.

Franz W.; Göggelmann K. and Winker P., [1998]: Ein makroökonometrisches Ungleichgewichtsmodell für die deutsche Volkswirtschaft 1960 bis 1994: Konzeption, Ergebnisse und Erfahrungen. In: U. Heilemann and J. Wolters (eds.): Gesamtwirtschaftliche Modelle in der Bundesrepublik Deutschland: Erfahrungen und Perspektiven, Schriftenreihe des RheinischWestfälischen Instituts für Wirtschaftsforschung 61, Duncker \& Humblot, Berlin 1998, 115 165.

Franz W. and König H., [1990]: A disequilibrium approach to unemployment in the Federal Republic of Germany. European Economic Review, Vol. 34, 413 - 422.

Franz W. and Smolny W., [1992]: Ungleichgewichte auf Arbeits- und Gütermärkten: Eine theoretische und ökonometrische Analyse mit Hilfe eines Mengenrationierungsmodells. In: W. Franz (ed.): Mikro- und makroökonomische Aspekte der Arbeitslosigkeit, Beiträge zur Arbeitsmarkt- und Berufsforschung No. 165, Nürnberg, 223 - 244.

Hansen L. P. and Heckman J. J., [1996]: The Empirical Foundations of Calibration, Journal of Economic Perspectives, Vol. 10, No. 1 (Winter), 87 - 104.

Jacobs O. H. and Spengel Chr., [1996]: European Tax Anayzer. EDV-gestützter Vergleich der Steuerbelastung von Kapitalgesellschaften in Deutschland, Frankreich und Großbritannien. Schriftenreihe des ZEW, Band 11, Baden-Baden.

Jacobs O. H. ; Spengel Chr.; Gröschel M.; Krahmer E.; Schmidt F. and Wünsche A., [1996]: European Tax Analyzer - Ein Computerprogramm für internationale Steuerbelastungsvergleich. Universität Mannheim, Lehrstuhl und Seminar für Allgemeine Betriebswirtschaftslehre, Treuhandwesen und Betriebliche Steuerlehre, 2. Auflage 1996, Mannheim.

Jensen S. E. H., [1997]: Debt Reduction, Wage Formation and Intergenerational Welfare. In: Broer D. P. and Lassila J. (eds.): Pension Policies and Public Debt in Dynamic CGE Models. Heidelberg, 167 - 189.

Lambert J.-P., [1988]: Disequilibrium Macro Models - Theory and Estimation of Rationing Models using Business Survey Data. Cambridge University Press, Cambridge.

Myers S. C., [1984]: The Capital Structure Puzzle. In: Journal of Finance, Vol. 39, 575 597.

Myers S. C. and Majluf N. S., [1984]: Corporate financing and investment decisions when firms have information that investors do not have. In: Journal of Financial Economics, Vol. 13, $187-221$.

OECD, [1994]: The OECD Jobs Study, Evidence and Explanations - The Adjustment Potential of the Labour Market. Paris.

Pissarides Chr. A., [1998]: The impact of employment tax cuts on unemployment and wages; The role of unemployment benefits and tax structure. European Economic Review 42, 155 $-183$.

Shoven J. B. and Whalley J., [1992]: Applying General Equilibrium. Cambridge, Mass.

Shoven J. B. and Whalley J., [1984]: Applied General-Equilibrium Models of Taxation and International Trade: An Introduction and Survey. Journal of Economic Literature, Vol. 22, 1007 - 1051.

Steiner V., [1998]: Employment and Wage Effects of Social Security Financing - An Empirical Analysis of the West German Experience and some Policy Simulations; in: Addison, J. T. and Welfens P. J. J. (eds.): Labor Markets and Social Security. Wage Costs, Social Security Financing and Labor Market Reforms in Europe, Springer-Verlag, Heidelberg. 
Tyrväinen T., [1995a]: Wage Determination in the Long Run, Real Wage Resistence and Unemployment: Multivariate Analysis of Cointegrating Relations in 10 OECD Economies, Bank of Finland, Discussion Papers, No. 12/95, Helsinki.

Tyrväinen T., [1995b]: Wage Setting, Taxes and the Demand for Labour: Multivariate Analysis of Cointegrating Relations, Empirical Economics, 20, 271 - 297. 